The results of this paper may be summarized as follows:

I. In the determination of carbon monoxicle by passing it over heated iodine pentoxide, the ends of the U-tube should be sealed off after filling, since the presence of organic matter, such as might come from the lubricant used with glass stoppers, also causes the decomposition of the iodine pentoxide, and would give too high results.

II. A modified method for carbon monoxide is presented, in which, after the iodine formed by the reaction is removed by a potassium iodide solution, the carbon dioxide is absorleed in barium hydroxide solution and cletermined by titration with oxalic acid. A check on the same sample can then be obtained, if desired, by titrating the iodine absorbed in the potassium iodide solution with $\mathrm{N} / \mathrm{r} 000$ sodium thiostulphate.

III. By placing another barium hychoxide tube before the one containing the iodine pentoxide, both the free carbon dioxide and the carbon dioxide produced by the free carbon nomoxide, can be determined in one operation by two titrations with the same reagent.

IAHOKATORY OF PIYSICAI. CHIMTSTR

september, ji:n?.

\title{
RAPID ANALYSIS BY ELECTROLYSIS WITHOUT ROTATING ELECTRODES.
}

FRANCIS C. HRARY.

Received Alugust 24, I90;

In a preliminary paper ${ }^{1}$ have described two forms of apparatus for the rapid determination of metals in the electrolytic way, without the use of a motor or rotating electrodes. The purpose of this paper ${ }^{2}$ is the description of the improved forms of this apparatus ${ }^{3}$ as they have been worked out since the earlier publication.

In the first apparatus (fig. I.) the solenoid consists of about 500 turns of $1.5 \mathrm{~mm}$. insulated copper wire (about No. $14 \mathrm{~B}$ and S gauge) and is wound on a copper cylinder $6 \mathrm{~cm}$. in diameter and I $\mathrm{cm}$. high. The flanges on the end of the cylinder are of sheet-iron. A hollow iron cylinder (height $4 \mathrm{~cm}$., thickness of irou $\mathrm{I} \mathrm{cm}$.) stands in the lower part of the copper cylinder. The solenoid is surrounded by an iron mantle, $2 \mathrm{~mm}$. thick, which serves the double purpose of protecting the insulation of the solenoid and of presenting a short path for the magnetic circuit on the outside of the coil. In this way the eutire magnetic force of the solenoid is concentrated in that portion of its core lying above the inner iron cylinder.

${ }^{1}$ Z. Elektrochem., I3, 308 .

${ }^{2}$ Also published in the $Z$. angew. Chem.

"D. R. G. M. applied for by the Vereinigten Fabriken für Laboratoriumshedarf, Berlin (American agents--The Kry-Scheerer Co., New York) who are sole owners of the right to manufacture the apparatus for sale, and to whom I am indebted for the

he two dtawings here published. 
With this apparatus a cylinder of platinum foil, or of platinum, copper, silver or nickel gauze, is used as cathode. The gauze cathode is preferable and should be large enough to fit the beaker quite closely. The beaker, which should hold about I25-15O cc., is supported by the iron cylinder in the core of the coil. I have used a spiral anode of the form shown in the cut, with good results. If it were desired to use this apparatus for the separation of the metals under graded cathode-potential as recommended by Sand ${ }^{1}$, the spiral could be made broader in order to

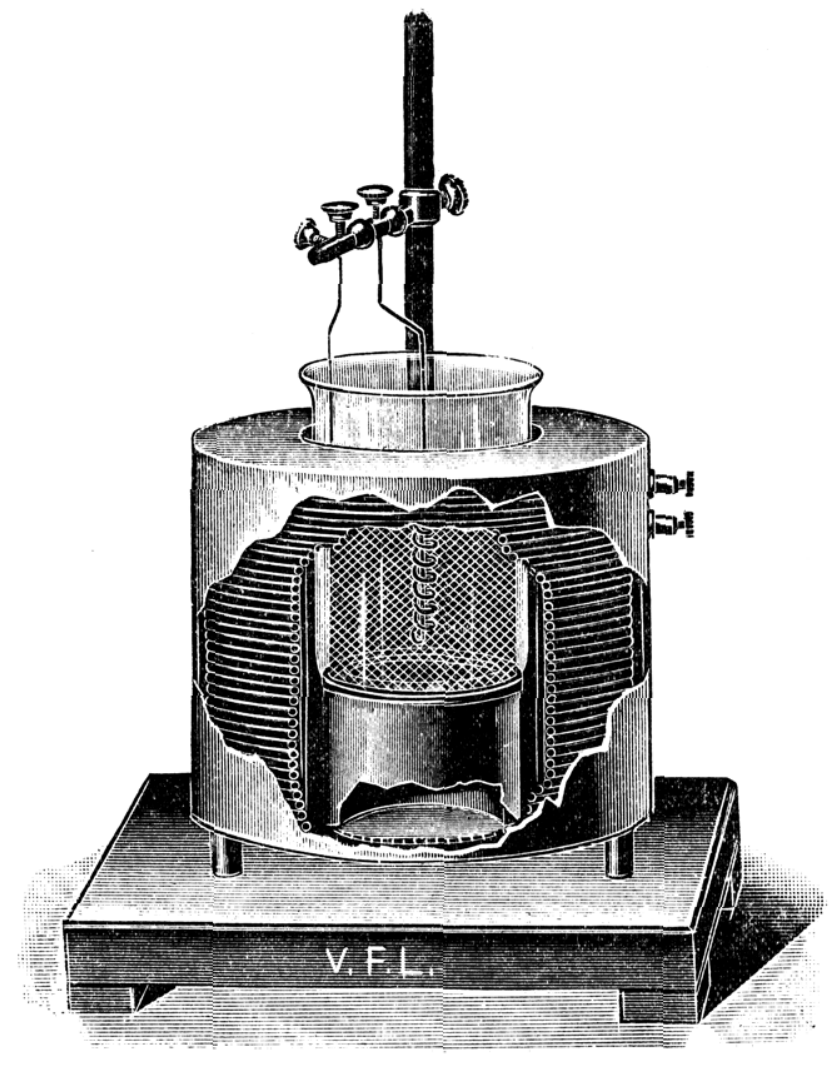

FIGURE I

secure the necessary low resistance of the bath. The electrolyte should, in general, just cover the cathode.

The electrolytic cell and the solenoid are generally connected in series so that only one source of current is required. The resistance of the coil is about one ohm, and five amperes may be sent through it for a long time without danger of overheating. As many electro-analytical methods require that the solution be heated, the heat developed in the coil is often

${ }^{1}$ J. Chem. Soc., 9r, 373 . 
no disadvantage. In cases where this heat is not desired, a smaller beaker ( $125 \mathrm{cc}$ ) ) is used. This is surrounded by a spiral of lead pipe (4 mm. ) through which water flows. If it is desired to use a small current for the electrolysis, the solenoid may be excited wholly or in part by a separate circuit.

For currents of more than 6 amperes the same method may be used, or a shunt may be used in parallel with the coil. If several pieces of the apparatus are in continual use in the same laboratory, all the coils may be connected in series and excited by the same current. The currentstrength for each analysis is then regulated independently of all the others and of that through the coils.

When the current flows through the solenoid, a uniform magnetic field is produced in the beaker, the lines of force being vertical. If, now, the current passes from one electrode to the other through the electrolyte, the lines of current in the latter are radial and horizontal. Every infinitesimal strip of electrolyte between the electrodes acts as if it were a wire carrying a current. The current direction is in every case perpendicular to the magnetic lines of force, which, therefore, push the electrolyte in a direction perpendicular to their direction and to that of the current. In other words, every particle of the electrolyte between the electrodes is acted on by a horizontal force which pushes it in a direction perpendicular to a radius of the cylinder drawn through it. The whole electrolyte therefore revolves about the anode as a cylinder about its axis. The cathode is naturally the limit of the current lines, yet the portion of the electrolyte between it and the walls of the beaker tevolves also, although much more slowly.

The same principle is used in the second apparatus (fig. 2) but the relative directions of the field and current are reversed. This apparatus is designed for use with a mercury cathode, the current lines are vertical, and a magnetic field of radial direction is therefore necessary. The $c$ athode cell has been made larger than that generally recommended, ${ }^{\text {in }}$ order that a volume of $100-125 \mathrm{cc}$. of electrolyte may be used as conveniently as the volume of $10-20$ cc. usually recommended. Richards and Bisbee ${ }^{2}$ have shown that precipitation is much more rapid from a small volume of solution, nevertheless the time lost in the evaporation of the larger volumes of liquid usually obtained in analytical work, would often be more than that gained by the more rapid precipitation from the smaller volume.

In order to obtain the radial magnetic field necessary for the rotation, the cathode-cell is made so that it has, in cross section, the form of a ring,

${ }^{1}$ i. e. by Smith and Kollock: This Journal, 27, I255, and Price and Judge, Chem. News, 94, I8 ( I906).

2 This Journal, 26, 530 . 
as shown in the cut, and one pole of the magnet extends up into the inner tube. The other pole is brought up around the solenoid so that it takes the form of a ring surrounding the cell. The lines of force have thus an iron path through the whole magnetic circuit except where the cell stands, and practically the whole magnetic force of the solenoid is

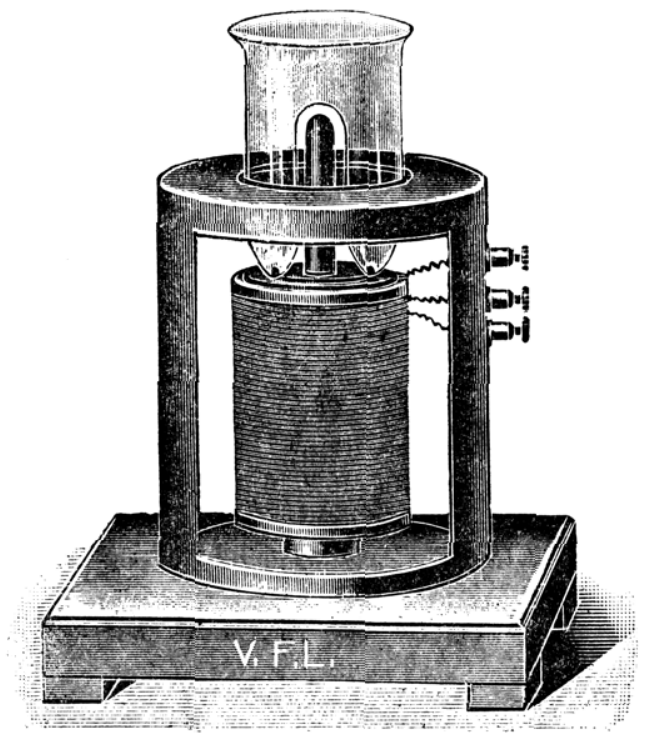

FIGURE 2.

concentrated in this gap, just where it is desired. The very strong "stray field" of the earlier model is thus avoided. The diameter of the cathode cell is $5 \mathrm{~cm}$. and its height IO $\mathrm{cm}$. It has a capacity of $200 \mathrm{cc}$. and thus gives room for the rather strong boiling and frothing which sometimes takes place. It is made of Jena glass, and rests upon three platinum wires fused into the glass and projecting into the mercury inside. The coil has 500 turns of $\mathrm{I}$. I mm. insulated copper wire (No. I $6 \mathrm{~B}$ and $\mathrm{S}$ gauge) and is wound on an iron core $1.6 \mathrm{~cm}$. in diameter. On the upper end of the coil is fastened an insulated copper plate, which is connectea with the negative pole of the source of current, and makes contact with the mercury cathode through the above-mentioned platinum wires.

In order to measure the rate of stirring of the liquid in this cell, a fragment of filter-paper was thrown into it and a current of 3.4 amperes sent through the cell and coil (connected in series). Both the path and speed of the paper were irregular; at times it would sink to the surface of the mercury and then again it would rub on the anode. I counted the number of revolutions per minute and found in three trials the numbers roo, IO2 and ro4. With the use of larger currents I was unable to measure 
the rate of stirring, as it was too great for even an approximate counting of the number of turns per minute. This is easily explained when we consider that the force propelling the liquid increases with the current passing through the solution and also with the increase of strength of the magnetic field. Thus when the cell and the coil are connected in series, this force would be approximately proportional to the square of the current. As a matter of fact the rate of stirring would not rise as fast as this, on account of the rapid increase of friction in the liquid with its increasing speed.

It should also be mentioned that the botton of the cell is preferably not flat, but $V$-shaped as shown in the cut, in order that a small amount of mercury may form a complete ring on it. If $40 \mathrm{~g}$. of mercury be used, the total weight of the apparatus will be about $100 \mathrm{~g}$. and so within the capacity of an ordinary balance.

Since the requirement of a motor has been one of the most objectionable features of the rapid methods for electro analysis, it is hoped that this apparatus by avoiding the use of all moving parts, will facilitate the introduction of these methods into practical work.

LNIVERSITY OF MINNESOTA,

Minneapolis, Minn.

Aug. 20, 1907 .

\section{THE RAPID DETERMINATION OF ZINC BY ELECTROLYSIS.}

\section{FKANCIS C. FRARY.}

Received Angust 2:, 190\%.

A great many methods have been proposed for the determination of zinc with the use of stationary electrodes; the use of solutions containing oxalates, citrates, acetates, lactates, formates, cyanides and phosphates being recommended by various authors. The use of a potassium zincate electrolyte is strongly recommended by Amberg" who obtained unsatisfactory results with the sodium zincate electrolyte recommended by Millot $^{3}$, v. Foregger ${ }^{4}$, and others. Spitzer ${ }^{3}$ has shown that the sodium zincate method gives good results with a nickel gaue cathode, and that while Amberg required $40 \mathrm{~g}$. of $\mathrm{KOH}$ for $0.5 \mathrm{~g}$. zinc, the amount of $\mathrm{NaOH}$ required is only a few g., barely enough to give a clear solution.

With a rotating anode, using a silver-plated platinum dish as cathode, Exuer, ${ }^{6}$ Ingham, ${ }^{7}$ and Miss Langness, ${ }^{8}$ have obtained concordant results

${ }^{\prime}$ Also published in $Z$. angew. Chem.

2 Ber., 36, 2489 (1903).

B Bull. soc, chim, 37, 339.

4 Dissertation Bern., 1896.

57 . Elektrochem., I I, 39 r.

6 'This Journal, 25, $\mathrm{S}_{96} 6$.

i Ibid., 26, 1269.

${ }^{8}$ Ibid., 29, 459. 